\title{
COVID-19 and Breastfeeding
}

El-Gilany $\mathrm{AH}^{1^{*}}$

${ }^{1}$ Professor of Public Health, Faculty of Medicine, Mansoura University, Egypt

Corresponding Author: Abdel-Hady El-Gilany MD

Address: Professor of Public Health, Faculty of Medicine, Mansoura University, Mansoura 35516, Egypt; Tel: o0201060714481; E-mail: ahgilany@gmail.com

Received date: 04 April 2020; Accepted date: 10 April 2020; Published date: 01 May 2020

Citation: El-Gilany AH. COVID-19 and Breastfeeding. Asp Biomed Clin Case Rep. 2020 May 1;3(2):102-105.

Copyright (C) 2020 El-Gilany AH. This is an open-access article distributed under the Creative Commons Attribution License, which permits unrestricted use, distribution, and reproduction in any medium provided the original work is properly cited.

\section{Abstract}

This editorial highlights the most recent updates on breastfeeding in the era of the COVID-19 pandemic. Possible modes and risk of transmissions, preventive measures to be taken in hospitals and homes as well as current recommendations were discussed.

\section{Keywords}

Breastfeeding; Breast Milk; COVID-19

Early initiation of breastfeeding has been shown to have positive effects on the neonate when done within an hour after birth. Both rooming-in and continuous skin-to-skin contact should be encouraged [1]. Breast milk is the best nutrient for infants, as it contains antibodies that enhance the infant's immune system $[2,3]$. WHO [4] recommended that infants should be breastfed exclusively for six months and continue breastfeeding with appropriate complementary foods for up to two years of age.

COVID-19 is an emerging respiratory illness caused by a new coronavirus that was first described in December 2019 during an outbreak in Wuhan, China. Based on what is currently known COVID-19 spreads from person-to-person via respiratory droplets among contacts within two meters of patients or carriers of the virus and by direct contact with infectious secretions from patients (e.g. sputum, serum, blood, respiratory droplets). The symptomatic people are believed to be most contagious. Spread from asymptomatic carriers might be possible, but this may not be the main mode of spread.

As of now, the virus has not been found in breast milk, and there is no current evidence for transmission by breastfeeding or feeding of expressed milk by bottle [5]. Currently, it is not clear if pregnant women have a greater probability of getting neither COVID-19 than the adult population nor whether they are more likely to have a severe illness. However, the few data from China do not show an increased risk of acquiring or severity of infection in pregnant women compared to non-pregnant.

A case series study of pregnant women with COVID-19, the virus was not detected in neonates or specimens of breast milk or amniotic fluid. It is of concern whether the virus can be transmitted from the mother to her newborn after birth, through respiratory droplets. There have been few cases of newborns with infection in the early days of life. It's not clear for researchers how COVID-19 might affect the fetus. Also is not clear if the virus can pass to a 
Editorial

fetus during labor and delivery.

Breast milk samples from the mothers after the first lactation were also all negative for the COVID-19 virus [6-8]. CDC [9] reported that the virus was not found in the breast milk of women with COVID-19 but antibodies to fight it have been found. Schwartz [10] in his analysis of 38 pregnant with COVID-19 and their newborn infants concluded that at this point in the pandemic of COVID-19 there is no evidence that SARSCoV-2 undergoes intrauterine or trans-placental infection from pregnant women to their fetuses. However, Dong, et al [11] reported a newborn with elevated IgM antibodies to SARS-CoV-2 born to a mother with COVID-19.

The current recommendations of UNICEF, UNFPA, $\mathrm{ABM}, \mathrm{WHO}$ and the $\mathrm{CDC}$ are that mothers and infants should remain together (rooming-in) and practice continuous skin-to-skin contact, particularly immediately after birth during initiation of breastfeeding, whether either of them has suspected, probable, or confirmed COVID-19. Infants born to these mothers should be fed according to standard newborn feeding guidelines with the application of all precautions of prevention and control of infection.

If the mother has severe COVID-19 infection or complications prevent her from continuing breastfeeding or caring for her infant she should be supported and encouraged to express milk and provide it to the infant, while applying appropriate precaution of infection prevention. The possibilities of re-lactation and donor human milk should be considered [2,12-15]. While in the hospital a well mother with only exposure or is under investigation for mild symptoms, breastfeeding is a very reasonable choice with taking the necessary respiratory and hand-washing precautions.

If the mother has COVD-19 she expresses milk for her infant. Limiting the infant's exposure via respiratory secretions may require more careful adherence to the recommendations depending on the mother's illness. Rooming-in is allowable without any other patients in that room with the infant kept in a bassinet two meters from the mother's bed and taking measures to prevent spreading the virus to her infant. There should be another healthy adult who cares for the newborn in the room. It is recommended to temporarily separate the infant from the mother because the mother severe COVID-19 infection requiring medical care in the hospital.

Mothers who intend to breastfeed/continue breastfeeding should express their breast milk to establish and/or maintain milk supply. Another healthy caregiver should feed the newborn with the expressed milk. At home mothers with confirmed COVID-19 infection should remain separate (home isolation precautions) from other family members including the infant, except for breastfeeding. Another uninfected adult should take care of the infant's needs and feed the infant expressed breast milk [2,16-19].

In conclusion transmission of COVID-19 from mother to the newborn after birth, through breast milk and infectious respiratory secretions, is a concern. Much is still unknown about COVID-19; limited studies have shown that the virus is not detected in breast milk; however, we do not know whether mothers with COVID-19 can transmit the virus via breast milk. There are no recommendations to separate asymptomatic women from their babies even if there has been a possible COVID-19 exposure.

Current advice is to continue breastfeeding and to take all possible respiratory precautions and distancing to prevent spreading the virus to the infant. However, these recommendations may change with the rapidly evolving guidelines. Future studies on the protective functions and safety of breast milk during the coronavirus pandemic are needed.

\section{Conflict of Interest}

None

\section{Funding}

None

\section{Data Availability Statements}

Not applicable 


\section{References}

[1] WHO Guideline: protecting, promoting and supporting breastfeeding in facilities providing maternity and newborn services. Geneva: World Health Organization; 2017. Available from: https://www.who.int/nutrition/publications/guidelin es/breastfeeding-facilities-maternity-newborn/en/

[2] ABM (Academy of Breastfeeding Medicine. ABM Statement on Coronavirus 2019 (COVID-19). 2020; 2020 Mar 10. Accessed: 2020 Mar 31. Available from: https://www.bfmed.org/abm-statement-coronavirus [3] CDC (Centers for Diseases Control and Preventions). Coronavirus Disease 2019 (COVID-19). Pregnancy and Breastfeeding; 2020. Accessed: 2020 Mar 28. Available from:

https://www.cdc.gov/coronavirus/2019-ncov/needextra-precautions/pregnancy-breastfeeding.html

[4] WHO. The optimal Duration of Exclusive Breastfeeding A systematic Review; 2001. Accessed: 2020 Mar 30. Available from:

https://www.who.int/nutrition/publications/optimal_ duration_of_exc_bfeeding_review_eng.pdf

[5] CDC (Centers for Diseases Control and Preventions). Coronavirus Disease 2019 (COVID-19). How Coronavirus Spreads; 2019. Accessed: 2020 Mar 30. Available from:

https://www.cdc.gov/coronavirus/2019-

ncov/prevent-getting-sick/how-covid-spreads.html

[6] Chen H, Guo J, Wang C, Luo F, Yu X, Zhang W, Li J, Zhao D, Xu D, Gong Q, Liao J, Yang H, Hou W, Zhang Y. Clinical characteristics and intrauterine vertical transmission potential of COVID-19 infection in nine pregnant women: a retrospective review of medical records. Lancet. 2020 Mar 7;395(10226):809-815. [PMID: 32151335]

[7] Wang X, Zhou Z, Zhang J, Zhu F, Tang Y, Shen X. A case of 2019 Novel Coronavirus in a pregnant woman with preterm delivery. Clin Infect Dis. 2020 Feb 28. pii: ciaa20o. [PMID: 32119083]

[8] Zhu H, Wang L, Fang C, Peng S, Zhang L, Chang G, Xia S, Zhou W. Clinical analysis of 10 neonates born to mothers with 2019-nCoV pneumonia. Transl Pediatr. 2020 Feb;9(1):51-6o. [PMID: 32154135]

[9] CDC. Coronavirus Disease 2019 (COVID-19). Pregnancy and Breastfeeding. Information about Coronavirus Disease 2019. 2020a; 2020 Mar 6 . Accessed: 2020 Mar 8. Available from: https://www.cdc.gov/coronavirus/2019ncov/specific-groups/pregnancy-faq.html [10] Schwartz DA. An Analysis of 38 Pregnant Women with COVID-19, Their Newborn Infants, and MaternalFetal Transmission of SARS-CoV-2: Maternal Coronavirus Infections and Pregnancy Outcomes. Arch Pathol Lab Med. 2020 Mar 17. [PMID: 32180426]

[11] Dong L, Tian J, He S, Zhu C, Wang J, Liu C, Yang J. Possible Vertical Transmission of SARS-CoV-2 From an Infected Mother to Her Newborn. JAMA. 2020 Mar 26. [PMID: 32215581]

[12] CDC. Interim Guidance for Implementing Home Care of People Not Requiring Hospitalization for Coronavirus Disease 2019 (COVID-19). 2020b; 2020 Feb 12. Accessed: 2020 Mar 31. Available from: https://www.cdc.gov/coronavirus/2019ncov/downloads/guidance-home-care.pdf

[13] WHO. Clinical management of severe acute respiratory infection (SARI) when COVID-19 disease is suspected. Interim guidance; 2020 Mar 13: WHO reference number: WHO/2019-nCoV/clinical/2020.4. Accessed: 2020 Mar 31. Available from:

https://www.who.int/publications-detail/clinicalmanagement-of-severe-acute-respiratory-infectionwhen-novel-coronavirus-(ncov)-infection-is-suspected [14] UNICEF. Coronavirus disease (COVID-19): What parents should know. How to protect yourself and your children? 2020. Accessed: 2020 Mar 31. Available from:

https://www.unicef.org/stories/novel-coronavirusoutbreak-what-parents-should-know

[15] UNFP. UNFPA statement on novel coronavirus (COVID-19) and pregnancy; 2020. Accessed: 2020 Mar 31. Available from:

https://www.unfpa.org/press/unfpa-statement-novelcoronavirus-covid-19-and-pregnancy

[16] EMBA (European Milk Bank Association). COVID19: EMBA Position Statement; 2020 Feb 25. Accessed: 2020 Mar 31. Available from:

https://europeanmilkbanking.com/covid-19-embaposition-statement/

[17] Morris E, O’Brien P, Goodyear G, Relph S, Jardine J, Powell A, Gilgunn-Jones E, Mullins E, Viner R, Evans D. Coronavirus (COVID-19) Infection in Pregnancy. Information for healthcare professionals. Royal College of Obstetrics and Gynaecology. 2020 Mar 9;6:1-45. 
Citation: El-Gilany AH. COVID-19 and Breastfeeding. Asp Biomed Clin Case Rep. 2020 May 1;3(2):102-105.

\section{Editorial}

[18] Mullins E, Evans D, Viner RM, O'Brien P, Morris

E. Coronavirus in pregnancy and delivery: rapid review. Ultrasound Obstet Gynecol. 2020 Mar 17.

[PMID: 32180292]

[19] PAHO (Pan American Health Organization). COVID-19, pregnancy, childbirth and breastfeeding; 2020 Mar 25. Accessed: 2020 Mar 31. Available from: https://www.paho.org/clap/index.php? 